\title{
Identification of a Forebrain Motor Programming Network for the Learned Song of Zebra Finches
}

\author{
Eric T. Vu, Mark E. Mazurek, and Yu-Chien Kuo \\ Division of Biology, California Institute of Technology, Pasadena, California 91125
}

\begin{abstract}
The stereotyped delivery of sequences of vocalizations by singing zebra finches is thought to be mediated by a "central motor program." We hypothesized that electrically stimulating, and thus perturbing, the neural components of this motor program during singing should alter the subsequent singing pattern. In contrast, perturbing the activity of other neurons in the song motor pathway that do not participate directly in generating the song temporal pattern should not affect the singing pattern. We found that unilaterally stimulating the forebrain area RA of singing birds with chronically implanted electrodes distorted ongoing syllables without changing the order or timing of ensuing syllables. However, stimulating forebrain area $\mathrm{HVc}$, which projects directly to RA, altered both ongoing syllables and the ensuing song pattern. These findings indicate that syllable sequencing during singing is organized in forebrain areas above RA (including HVc) and that the resulting pattern is imposed on lower structures of the motor pathway. Furthermore, the observation that unilateral forebrain perturbation was sufficient to alter the pattern of this bilaterally organized behavior suggests that (nonauditory) feedback pathways to the forebrain exist to coordinate the two hemispheres during singing. We suggest that the study of the motor control system for birdsong has provided the most direct evidence to date for localizing the programming of a skilled motor sequence to the telencephalon.
\end{abstract}

[Key words: birdsong, song system, central pattern generation, motor control, brain electrical stimulation, motor programming, vocalization, songbird]

There is much indirect evidence that the telencephalon participates in "programming" voluntary behavior (Bernstein, 1967; Rothwell et al., 1982, 1989; Carter and Shapiro, 1984; Marsden et al., 1984; Sanes et al., 1985; Ghez et al., 1991), including the findings that many different neurons in the telencephalon are more active before and during movement (Evarts, 1968; Brinkman and Porter, 1979; Bock et al., 1987; Humphrey and Freund, 1991; Mushiake et al., 1991; Kalaska et al., 1992). However, little evidence exists that localize a particular motor program to a discrete telencephalic brain area (Alexander et al., 1992).

\footnotetext{
Received Mar. 29, 1994; accepted May 5, 1994.

We thank M. Oei for technical assistance, M. Konishi for help with cochlear removal, and D. Perkel, M. Schmidt, A. Doupe, and M. Konishi for discussion. This work was supported by an individual National Research Service Award to E.T.V. and funds from the Bing Behavioral Biology Chair to M. Konishi.

Correspondence should be addressed to Dr. Eric Vu, Division of Biology 216 76, California Institute of Technology, Pasadena, CA 91125.

Copyright (C) 1994 Society for Neuroscience $0270-6474 / 94 / 146924-11 \$ 05.00 / 0$
}

This is in contrast to the good evidence that localized neural networks called "central pattern generators" exist in the brainstem and spinal cord that encode the motor programs for certain rhythmic behaviors (Grillner and Wallen, 1985; Feldman, 1986; Grillner et al., 1991; Pearson, 1993). We present here the first direct demonstration that a motor program for a learned motor sequence is localized to a discrete network of neurons in the telencephalon.

The song of adult zebra finches (Fig. 1A) has been hypothesized to be organized by a "central motor program" (Konishi, 1965,1985 ) because of its highly stereotyped form and its continued stereotypy following removal of auditory feedback by deafening. The neural network controlling this behavior is one of the best-characterized behavior-producing networks in the vertebrate telencephalon (Fig. 1B; Konishi, 1989). In particular, discrete forebrain areas are known to be necessary for song control (Nottebohm et al., 1976) and to show increased neural activity preceding and during song vocalizations (McCasland, 1987; Williams and Vicario, 1993). Furthermore, this telencephalic neural circuit is linked anatomically to the tracheosyringeal portion of the hypoglossal nucleus (nXIIts), which contains the motor neurons innervating the muscles of the syrinx, the avian vocal organ (Fig. 1B). However, this extensive knowledge does not indicate conclusively whether the telencephalon directly organizes song patterning or whether its role is merely permissive as it is for other patterned behaviors such as mastication, locomotion, or respiration (Chandler and Goldberg, 1984; Grillner and Wallen, 1985; Feldman, 1986).

To distinguish between these two roles and to localize the neurons directly participating in song patterning, we implanted chronic electrodes in specific forebrain areas in order to deliver brief electrical stimuli during singing. We hypothesized that if the specific sequence of song "syllables" is encoded centrally in discrete brain areas then briefly stimulating these areas would alter syllable sequencing. A similar strategy has been used to analyze the neural organization for other patterned behaviors (Pearson and Fourtner, 1975; Selverston and Moulins, 1985). Its success depends on demonstrating not only that stimulating a specific part of the motor pathway perturbs behavioral patterning but also that stimulating "downstream" from this area, especially areas to which its neurons project directly, fails to alter the subsequent behavioral pattern (Young, 1989).

We report here that perturbing the neural activity in the telencephalic area " $\mathrm{HVc}$ " (formerly the hyperstriatum ventrale, pars caudale) of behaving animals alters the subsequent singing pattern, thus localizing the function of organizing the order and tempo of a sequence of movements to a telencephalic brain arca.

An abstract of these data has been published (Vu et al., 1993). 


\section{Materials and Methods}

Animals and surgery. Adult (>90 d posthatch) male zebra finches (Taeniopygia guttata) were obtained from our breeding colony or from a commercial breeder. They were anesthetized with Equithesin $(2 \mathrm{ml} / \mathrm{kg}$, i.m.) and placed in a stereotaxic head holder. The skull was exposed, a small hole was made over the brain area of interest, a small incision was made in the dura mater, and an electrode was lowered into the brain to the appropriate depth. The electrode was then held in place by cementing its connector to the skull with dental acrylic. All electrodes were placed using stereotaxic coordinates from a laboratory atlas of the zebra finch brain. For each bird, one electrode was implanted in each hemisphere. A stainless steel wire was also inserted under about $4 \mathrm{~mm}$ of scalp and cemented to the skull to provide the return ground path for stimulating currents. To increase the frequency and stereotypy of singing behavior, Silastic pellets containing testosterone proprionate were implanted subcutaneously under the wing pits (Gurney, 1981). Three birds were deafened by bilateral cochlear removal, as described by Konishi (1965).

Electrodes. Monopolar electrodes were fabricated from Formvar-insulated stainless steel wire (California Fine Wire, Grover City, CA) and had $125 \mu \mathrm{m}$ tips and impedances of 50-200 k $\Omega$ (at $1 \mathrm{kHz}$ ). One HVc was implanted with an electrode that had a longer taper and thus a smaller tip diameter. This electrode was fabricated from a $125 \mu \mathrm{m}$ tungsten rod etched to a tip of about $15 \mu \mathrm{m}$ and coated with Epoxylite (Epoxylite Corp., Irvine, CA) to about 20-30 $\mu \mathrm{m}$ from the tip. This electrode had an impedance of about $600 \mathrm{k} \Omega$. Because the physical spacc taken up by the tip of this electrode was smaller than that occupied by the stainless steel electrodes, the etched tungsten electrode produced less physical damage in the brain. The effects of stimulating with either kind of electrode were not distinguishable.

Description and terminology of song. The vocalizations produced by singing birds can be classified precisely by analyzing their spectrograms (Fig. $1 A$ ), thus obviating the need to measure muscular activity from behaving animals in order to quantify motor output. To describe clearly the "songs" of zebra finches, we use the terminology of Sossinka and Böhner (1980): a "strophe" of an adult zebra finch consists of a series of "introductory notes" followed by one or more "motifs," which consist of a sequence of syllables sung in a specific order and tempo (a syllable is defined as a marking on the sound spectrogram that lasts at least 20 msec and is surrounded by intervals of baseline energy lasting at least $10 \mathrm{msec}$ ). The two most stereotyped features of zebra finch song are the spectral shape of individual syllables and the sequence and durations of the syllables and silent intervals within the motif.

Experimental sessions. After electrode implantation, birds were kept isolated in sound-attenuating chambers (Industrial Acoustics Company, Inc., New York, NY) for at least $2 \mathrm{~d}$ before being subjected to stimulating sessions. They were provided with food, gravel, and water ad libitum. At the start of each experimental session, leads from a commutator connected to the stimulus isolator were attached to the connectors cemented on the bird's head. Only one brain site was stimulated per session, which did not last more than $1 \mathrm{hr}$. A female zebra finch was introduced in the chamber to induce directed songs (Sossinka and Böhner, 1980) and was removed from the chamber at the end of the session. Electrical stimuli to the brain were generated by an Anapulse 302-T stimulator (World Precision Instruments, New Haven, CT) early in the study and later by an AM-Systems 2100 stimulator (Seattle, WA). The AM-Systems stimulator contains an error light indicator for breaks in the current path, but this was also checked regularly along with the amount of current delivered to the animal by measuring the voltage drop across a $1 \mathrm{k} \Omega$ resistor connected in series with the animal. A microphone (Realistic PZM, Radio Shack, Fort Worth, TX) was placed in the chamber and vocalizations and the timing of stimulus trains were simultaneously recorded with a two-channel reel-to-reel tape recorder (TEAC 3300-S) at a speed of 19.1 inches/sec.

Stimuli applied during singing consisted of a train of 7 biphasic pulses at $400 \mathrm{~Hz}$, with a duration of $0.4 \mathrm{msec} / \mathrm{phase}$ (train duration approximately $16 \mathrm{msec}$ ) and were triggered manually. Longer stimulus trains were occasionally used exploratorily but their effects were not quantified because they are more difficult to interpret. Long stimulus trains more readily lead to transynaptic excitation of distant structures to which neurons near the electrode tip project (via temporal summation by the distant postsynaptic neurons; see Yeomans, 1990), making it more difficult to attribute a behavioral effect to the stimulation of a particular set of neurons. The choices of stimulus current amplitudes were based on preliminary findings: We found that 500 -msec-long stimulus trains
A

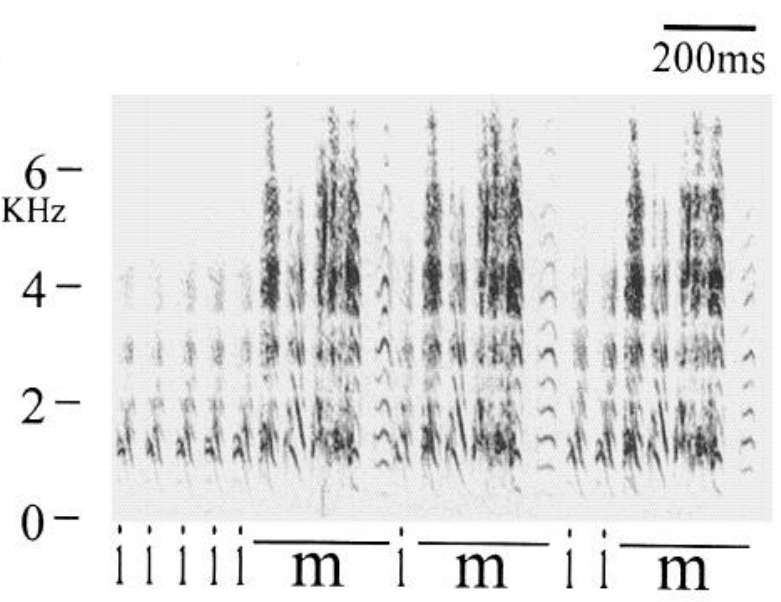

$\mathrm{B}$

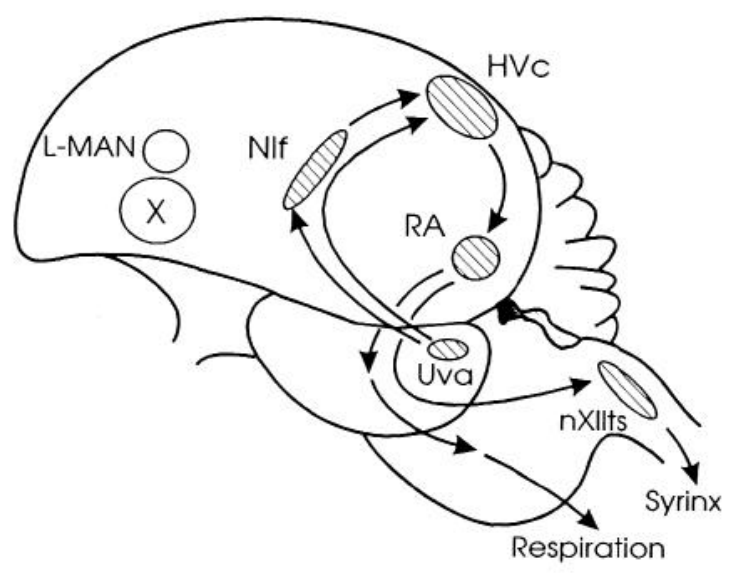

Figure 1. Zebra finch song and its neural substrates. A, Spectrogram (sound frequency spectrum vs time) of a typical strophe and its constituents: introductory notes $(i)$ and motifs $(m)$. The syllables and silent intervals within motifs have highly consistent durations. As a result, motif durations vary little. However, the number of motifs per strophe, intervals between motifs, and the number of introductory notes sung between motifs are variable. $B$, Schematic diagram of the motor pathway for song (hatched structures; arrows, anterograde projections). The connections of area $X(X)$ and of the latcral magnocellular nucleus of the anterior neostriatum $(L-M A N)$ are not shown. Uva, uvaeformis; NIf, interfacialis of the neostriatum; $H V C$, formerly the hyperstriatum ventrale, pars caudale; $R A$, robustus archistriatalis; $n X I I t s$, tracheosyringeal part of hypoglossal nucleus. The link between RA and respiratory motorneurons is multisynaptic (Wild, 1993, 1994). Note that HVc does not project directly to either NIf or Uva.

at current intensities of $30-40 \mu \mathrm{A}$ evoked vocalizations consistently from quiescent animals when the electrode tip was inside area HVc, indicating that higher current levels were not necessary to drive at least $\mathrm{HVc}$ neurons to fire. Areas other than $\mathrm{HV} c$ were often stimulated at current intensities higher than the above range as well. To compare the results of stimulating these areas and $\mathrm{HVc}$, the data sets of the former were divided into "low-intensity" $(30-40 \mu \mathrm{A})$ and "high-intensity" (45$70 \mu \mathrm{A})$ stimuli.

One to three stimulus trains were delivered during each strophe (depending on the duration of the strophe). The experimenter avoided triggering a stimulus after about the third motif in a strophe because of the relatively high likelihood that a strophe would end after the third motif is sung whether or not a stimulus is delivered at that time. "Control" strophes in which no stimulus was delivered were also collected from time to time.

Zebra finch song is a bilaterally organized behavior (McCasland, 1987). Because it is not possible to perturb exactly the same sets of neurons on both sides of the brain simultaneously, we stimulated the brain only unilaterally. 
Histology. After at least 70 control and stimulated motifs were collected, animals were deeply anesthetized with ketamine $(40 \mathrm{mg} / \mathrm{kg}, \mathrm{i} . \mathrm{m}$.) and Metofane (methoxyfurane; Pitman-Moore, Inc., Mundelein, IL) and perfused intracardially with $0.9 \%$ saline followed by $4 \%$ paraformaldehyde, $0.0025 \mathrm{M}$ phosphate-buffered solution. The chronic electrodes were fixed inside the brain for at least 3 more days before they were carefully removed and the brain then removed from the skull. (The relatively large electrode tip size and the thin lining of gliosis built up around both the tip and the shank of the electrode made electrolytic lesion for clectrode localization unnccessary.) Elcctrode tracks werc located on $40 \mu \mathrm{m}$ frozen sections stained with cresyl violet.

In total, we have obtained data from unilateral stimulation of 40 sites in the forebrain during singing. Six electrodes tips were histologically determined to be in area RA, four in HVc, four in $\mathrm{X}$, and three in L-MAN (see Fig. 1 for list of abbreviations). Others were found to be either outside the border of one of the above areas but not in any of its incoming or outgoing nerve tracts or just outside the area but in an area known to contain an input or output tract.

Data analysis. Taped data were analyzed off line with a Kay DSP Sona-Graph (Kay Elemetrics, Pine Brook, NJ) in order to identify syllables correctly in spectrograms and oscillograms. Sound and stimulus channels were filtered and digitized $(10 \mathrm{kHz})$ for measurement with the IBM PC-DOS program AXOTAPE (Axon Instruments, Foster City, CA). Following the conventions of Sossinka and Böhner (1980), a strophe (Fig. $1 \mathrm{~A}$ ) was characterized as a group of vocalizations that is preceded by at least $2 \mathrm{sec}$ of silence and that begins with a set of three or more introductory notes. Introductory notes sung between motifs were not classified as parts of the motif because they were neither preceded by a constant interval (from the last syllable of the previous motif) nor followed by a constant silent interval (see Price, 1979; Sossinka and Böhner, 1980). Similarly, "long" calls (Zann, 1985) that some zebra finches occasionally interposed between motifs were not considered parts of motifs.

For each recorded motif, we measured its duration, the duration of the silent interval between the end of the motif and the beginning of the next vocalization (an introductory note, a long call, or the next motif), and the duration between the end of the motif and the beginning of the next motif. If an electrical stimulus to the brain had been delivered during the motif, the time between the beginning of the motif and the onset of the stimulus was also measured. These values were obtained for all motifs during which a stimulus was delivered (18-65 per animal) and for the first 50 to 106 unstimulated (control) motifs.

Summary data in the Results are expressed as the mean \pm standard deviation. Error bars in the figures are standard errors of the means. All statistical analyses were paired $t$ tests except where noted.

\section{Results}

In general, the brief stimuli we applied to the forebrain did not simply stop singing behavior. Rather, they produced subtle perturbations of song that differed for stimulation of different brain areas. Because of its implications on the motor control of singing, we focused on one particular type of perturbation in this study: alterations in the sequence and timing of the syllables of the motif. We first describe this type of perturbation, which was observed most readily with low-intensity stimulation of $\mathrm{HVC}$ (see Materials and Methods for current values corresponding to low- and high-intensity stimulus ranges). Second, we show that this behavioral effect did not occur when we stimulated area RA, the part of the motor pathway to which HVc neurons project directly. Lastly, we present several lines of evidence that the change in motor sequencing was obtained only when the firing rate of $H V_{c}$ neurons was perturbed.

\section{Stimulating $H V_{C}$ during singing altered the subsequent syllable sequence}

We found two different types of changes in song patterning following unilateral $\mathrm{HVc}$ stimulation in either hemisphere. One type occurred only rarely, although it was observed at least once with each of the four electrodes successfully placed in HVc. The second type occurred much more frequently. Together, these two types of pattern change occurred following $74.8 \pm 15.3 \%$ of all stimuli across the four electrodes in HVc (two in the left and two in the right hemisphere).

In the first kind of pattern alteration, the stimulus to $\mathrm{HVc}$ caused a syllable or part of a syllable that was about to occur to be omitted and the rest of the syllables in the motif to be shifted forward in time, or caused a syllable to be repeated before the rest of the motif was sung (Fig. 2). We call these pattern changes "intramotif" perturbations. Their low incidence (2$16 \%$ of stimuli that altered song patterning at each of four $\mathrm{HVc}$ stimulation sites) precluded a more quantitative analysis. However, their occurrence clearly was linked to the stimulus because similar pattern changes wcre ncver scen in any of the more than 250 unstimulated motifs sung by the same animals.

The stimulus often suspended ongoing motifs. Unilaterally stimulating $\mathrm{HVc}$ frequently caused animals to suspend an ongoing motif within $70 \mathrm{msec}$ from the stimulus onset and to resume singing in the same strophe with the beginning of a new motif (Fig. 3).

The latency between the onset of the stimulus and the suspension of the ongoing motif was constant $(69.6 \pm 2.3 \mathrm{msec}$ across four $\mathrm{HVc}$ stimulation sites). Consequently, the sooner into a motif a stimulus was delivered, the shorter the duration of that motif (Fig. 4), and thus stimulated motifs tended to be much shorter than unstimulated motifs.

The stimulus did not suspend an ongoing motif by simply triggering a new motif prematurely because the motif that followed the suspended/stimulated motif in the strophe did not have a constant latency to the stimulus. In addition, the same type of stimulus did not induce any vocalization or evoke a motif when applied to quiescent birds.

The stimulus did not suspend ongoing strophes. The mean number of motifs in stimulated and unstimulated strophes did not differ significantly (stimulated $=3.0 \pm 0.6$; unstimulated $=$ $1.9 \pm 0.2 ; N=4 ; t=-3.05 ; P>0.05$ ), indicating that, unlike ongoing motifs, ongoing strophes were not suspended. This can be seen clearly in Figure 3, which shows that the animal continued to sing another motif following the stimulus. Singing continued after the stimulus was delivered for a majority of the stimuli ( $66 \pm 4 \%$ across four HVc stimulation sites). Therefore, stimulating HVc did not simply cause singing to stop.

The stimulus caused a temporal shift of succeeding motifs. In the example in Figure 3, it is clear that the motif following the suspended motif began sooner than it would have if a stimulus had not been delivered, indicating that the temporal structure of the remaining portion of the strophe was altered by the stimulus. This observation was consistent across the four different $\mathrm{HVC}$ stimulation sites. We measured the interval between the end of a motif and the beginning of the next motif and compared those following suspended motifs and control (full-length) motifs. There was no significant difference in this interval $(487 \pm$ $284 \mathrm{msec}$ following suspended motifs; $478 \pm 297 \mathrm{msec}$ following controls; $N=4 ; t=-0.59 ; P>0.05$; Fig. $5 A$ ), indicating that the motifs following suspended motifs were consistently shifted forward in time. Furthermore, there was no correlation between the interval to the next motif and the duration of the preceding suspended motif. The correlation coefficient between these two variables ranged between 0.03 and 0.20 for the four different HVc stimulation sites, indicating that shorter suspended motifs are not followed by longer intervals (Fig. $5 B$ ).

Thus, motifs made shorter by HVc stimulation are not followed by longer intervals to the next motif, indicating that the 
$A$
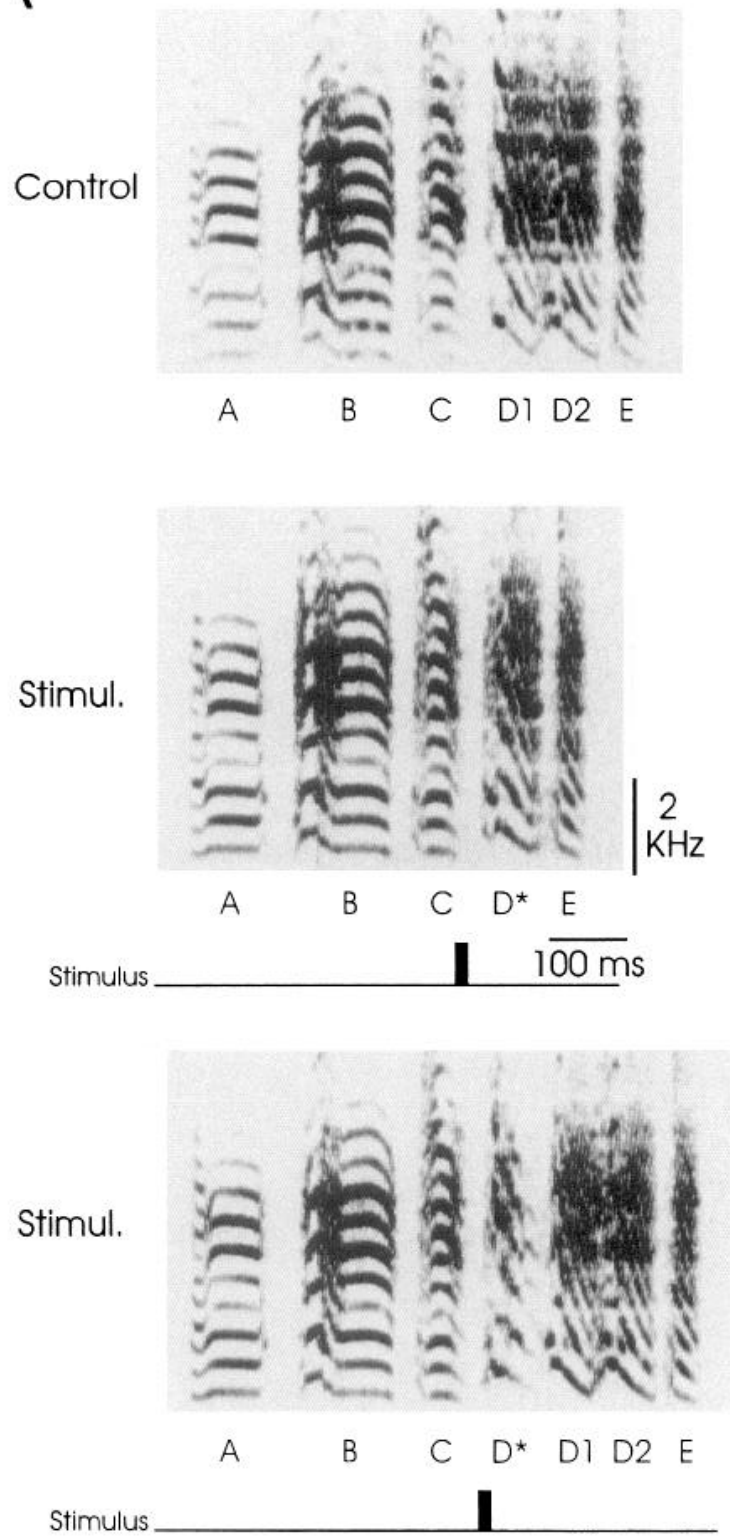

B

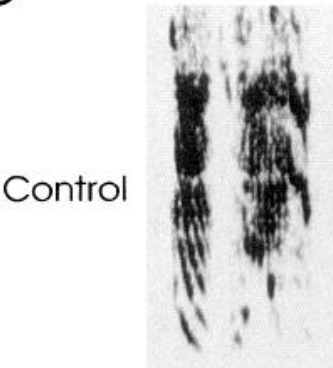

A B C
D

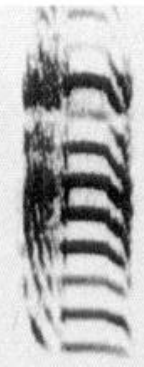

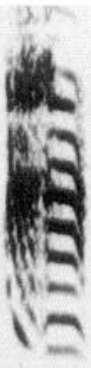

E

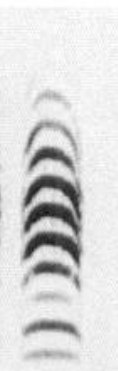

F

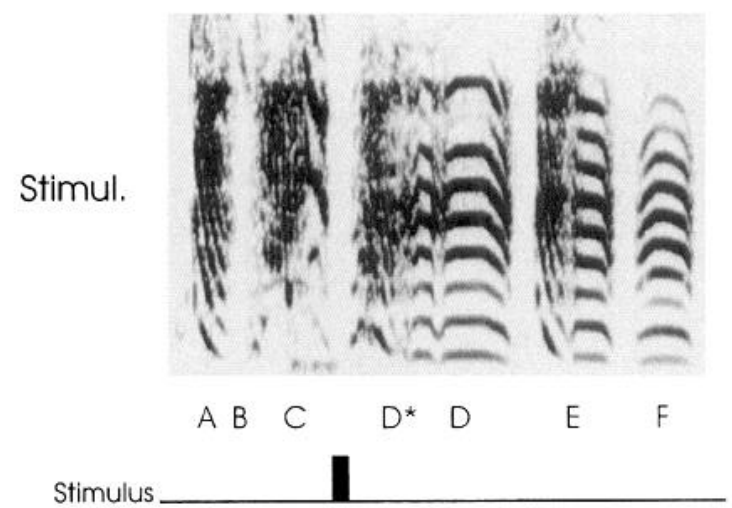

Figure 2. Examples of intramotif perturbations. A, The top spectrogram illustrates a motif sung when no brain stimulation was delivered, and the middle and bottom spectrograms show motifs sung by the same bird during which a stimulus to the left HVc was delivered at the time shown by the corresponding Stimulus trace below each spectrogram. The beginnings of the motifs in the three spectrograms are aligned. Letters under each spectrogram identify individual syllables. (The two components of syllable $D$ are labeled separately for easier identification in stimulated motifs.) An asterisk beside a letter indicates that the syllable acoustic structure was distorted by the stimulus. $B$, An intramotif perturbation from a different animal that was stimulated in the right HVc, shown with the same conventions.

next motifs are shifted forward in time and therefore that the temporal structure of the rest of the strophe is also altered by the brief stimulus to HVc.

Song perturbation was not mediated by auditory feedback. Stimulating HVc altered song patterning even in animals deafened by cochlear removal $(N=2$; in a third deafened animal, stimulating the output tract from HVc to RA also altered song patterning). Therefore, the change in temporal pattern of the strophe following a stimulus to $\mathrm{HVc}$ was not due to auditory detection of a mismatch between intent and motor performance that then led to feedback correction of the motor control system.

Stimulating the HVC-to-RA fiber tract also perturbed syllable sequencing. We investigated the possibility that the effects observed with HVc stimulation were due to the antidromic activation of axon terminals in $\mathrm{HVc}$ from neurons of other brain areas, such as NIf and Uva (see Fig. $1 B$ ).

We found a high percentage of motif suspension $(71.3 \pm 0.5 \%$; $N=4$ ) when stimulating at low intensity the area ventral and posterior to $\mathrm{HVc}$ where the large fiber bundles from $\mathrm{HVc}$ travel towards RA (Fig. 6). This result was not due to spread of the stimulating currents into $\mathrm{HVc}$ because stimulating other areas just outside the borders of $\mathrm{HVc}$ (by as little as $150 \mu \mathrm{m}$ ) did not cause motif suspension $(3.8 \pm 5.5 \%, N=5)$. Thus, stimulating only the axons of $\mathrm{HVc}$ neurons projecting to RA without stim- 

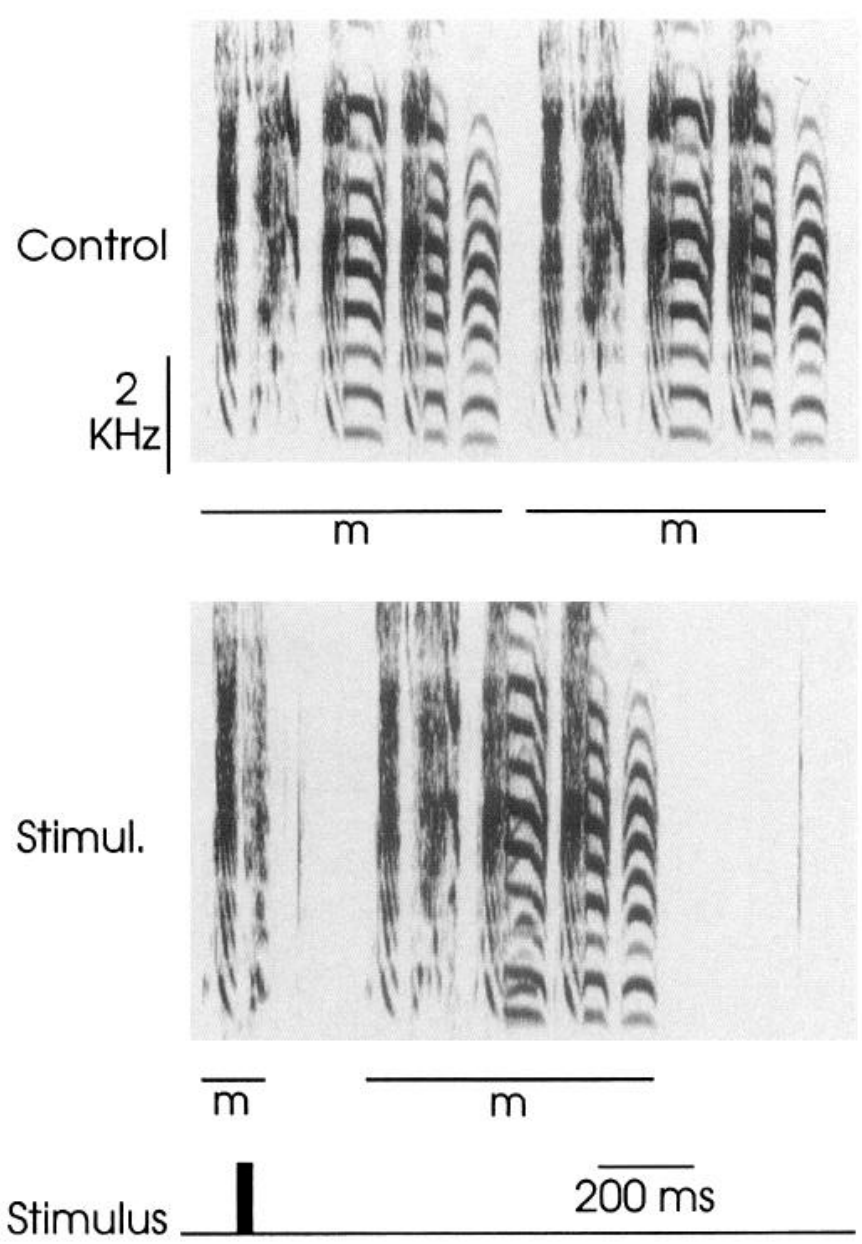

Figure 3. Predominant effects on singing of briefly stimulating HVc. The upper spectrogram shows two consecutive unstimulated motifs, each underlined and labeled $(\mathrm{m})$. The bird suspended an ongoing motif and rapidly resumed with a new motif soon after a stimulus to its right $\mathrm{HVc}$ (lower spectrogram). The beginnings of the first motifs in the upper and lower spectrograms are aligned, and the time of delivery of the stimulus is indicated by the bottom Stimulus trace. Note that the second motif in the lower spectrogram would have overlapped with the end of the first motif had it not been suspended.

ulating the inputs to $\mathrm{HVc}$ from other brain areas was sufficient to trigger motif suspension.

\section{Stimulating $R A$ distorts ongoing syllables without altering the subsequent syllable sequence}

Unilaterally stimulating inside area RA at low intensities consistently distorted the acoustic structure of an ongoing syllable without changing the order or timing of ensuing syllables $(N=$ 6 , one in the left and five in the right RA; Fig. 7). Despite this syllable distortion, which indicates that the stimuli succeeded in altering the firing rate of neurons in RA, we did not observe a consistent change in the temporal pattern of the rest of the song.

We calculated the percentage of stimuli at each electrode site that perturbed the pattern of ongoing motifs and compared these across groups of similar sites. Stimulating inside $\mathrm{HVc}$ at low intensities led to a high percentage of motif pattern perturbation (Fig. 8, group $1 ; 74.8 \pm 15.3 \% ; N=4$ ). In contrast, stimulating

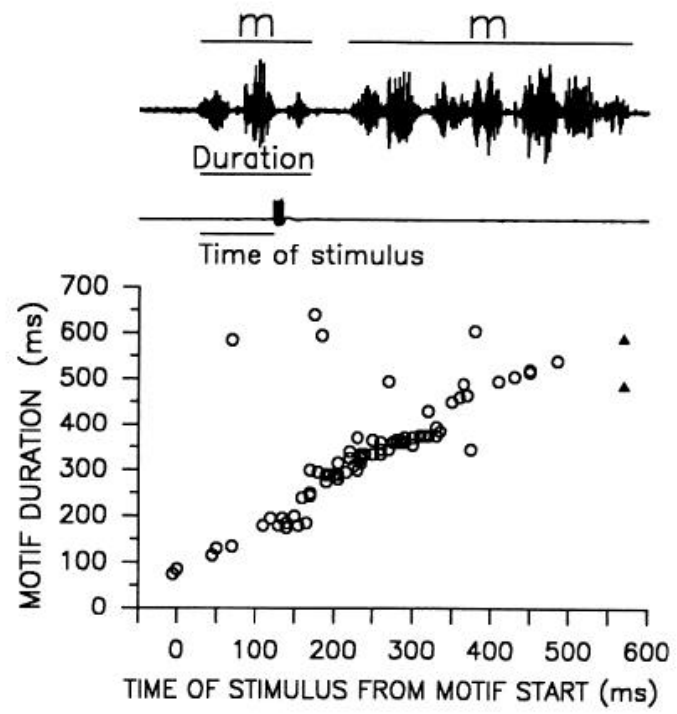

Figure 4. The time of motif suspension was well correlated to the HVc stimulus. The upper records illustrate the two values measured to construct the lower graph. One record is the oscillogram (sound amplitude vs time) of a song segment containing two motifs $(\mathrm{m})$, the first of which was suspended; the second record is the stimulus trace. In the lower graph, the durations of all stimulated motifs sung by the same animal as in Figure 3 are graphed against the onset time of the HVc stimulus relative to the motif start (circles). The durations of 96 of the 98 unstimulated motifs sung by this bird clustered closely around two mean values (triangles; the corresponding SD bars did not exceed the size of the triangles, reflecting the high stereotypy of the unstimulated motif pattern). In contrast, $90 \%$ of the stimulated motifs had durations that were more than two SD from either of these two mean values.

inside RA caused a significantly lower percentage of pattern perturbation (group $2 ; 17.2 \pm 16.0 \% ; N=5 ; t=5.45 ; P<$ 0.001 , unpaired $t$ test). Stimulating the HVc-to-RA tract also perturbed the motif pattern consistently (group 3 ), as described previously.

These observations indicate that the change in song patterning produced by stimulating $\mathrm{HVc}$ is not due simply to transynaptic activation of RA neurons (or more peripheral parts of the motor pathway for singing), or to antidromic activation of brain areas that project to $\mathrm{HVc}$.

\section{Antidromic activation of $H V c$ alters syllable sequencing}

If stimulating HVc-to-RA fibers was sufficient to trigger motif suspension, then stimulating inside RA sufficiently strongly to induce action potentials from HVc nerve terminals in RA should cause motifs to be suspended via antidromic activation of HVc.

We found that stimulating inside RA with high current intensities $(45-70 \mu \mathrm{A})$ caused motif suspensions as frequently as did direct HVc stimulation (Fig. 9, group 1; $61.4 \pm 16.7 \% ; N$ $=5$; compare with Fig. 8 , group 1).

Although this finding is consistent with antidromic activation of $\mathrm{HVc}$, it is possible that high- but not low-intensity stimulation of RA leads to motif suspensions because stronger stimuli perturb the firing rates of more RA neurons. To address this issue, we altered the firing pattern of RA neurons without the possibility of concurrently activating $\mathrm{HVc}$ by stimulating the second major input to RA, the lateral magnocellular nucleus of the anterior neostriatum (L-MAN). Although L-MAN is not critical for adult song production (Bottjer et al., 1984), electrical stim- 

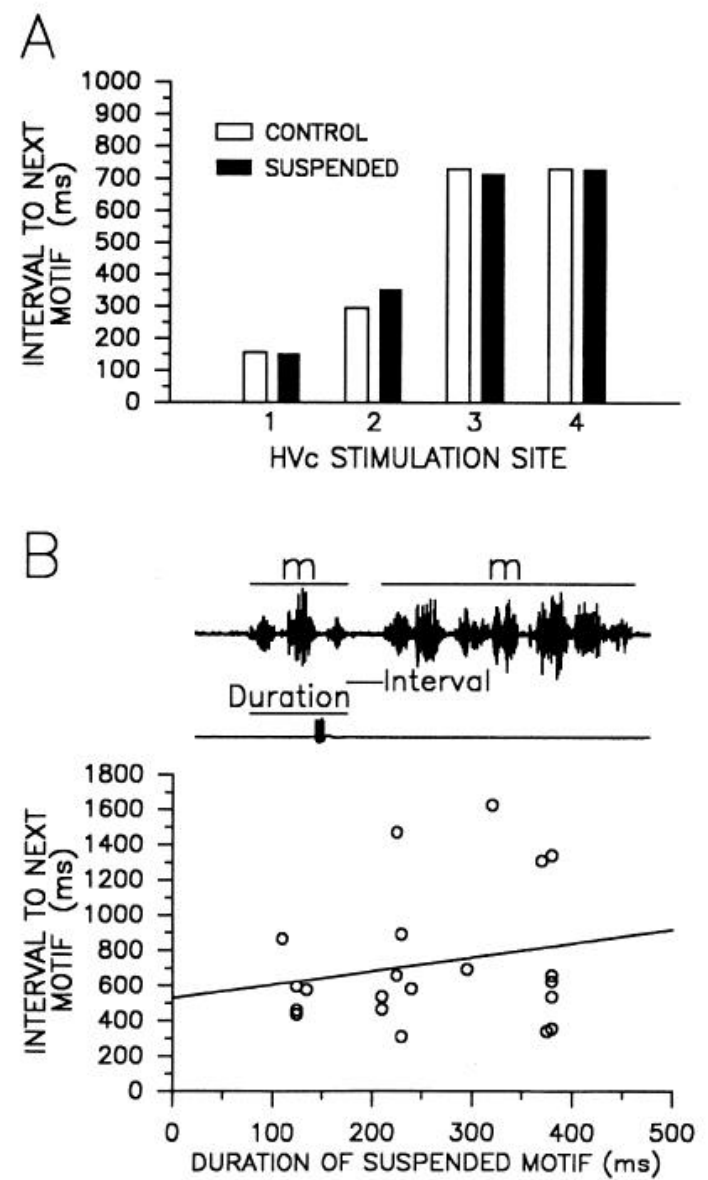

Figure 5. Temporal shift of motifs following suspended motifs. $A$, The mean intervals to the next motif following control and suspended motifs are shown for each stimulation site in HVc. If stimulating HVc suspended motifs but did not also shift the next motif forward in time, then this interval would have been longer following suspended motifs. $B$, For one animal, the interval to the next motif corresponding to all suspended motifs are graphed against the duration of the (preceding) suspended motif (circles) and the regression line for these data is shown. (See the inset above the graph for definitions of the measurements). The correlation coefficient associated with these data was 0.20 , indicating that the intervals did not vary as a function of the duration of the preceding motif.

ulation of L-MAN in vivo evokes bursts of multiunit activity in RA (Williams, 1989) and stimulating its fibers in brain slices evokes sizable excitatory postsynaptic potentials in RA neurons (Kubota and Saito, 1991; Mooney and Konishi, 1991; Mooney, 1992). Thus, strongly stimulating L-MAN during singing should distort the firing pattern of many RA neurons.

We found that stimulating L-MAN during singing did not induce a significant amount of motif suspension (Fig. 9, group $2 ; 10.7 \pm 7.0 \% ; N=3$ ), even when current intensities as high as $70 \mu \mathrm{A}$ were applied. This indicates that stimulating RA neurons without concurrently stimulating $\mathrm{HVc}$ neurons fails to trigger motif suspension, independent of the number of RA neurons affected. Therefore, strongly stimulating RA triggers motif suspension only because it activates $\mathrm{HVc}$ antidromically.

If antidromically activating $\mathrm{HVc}$ from RA causes motif suspension, then antidromically activating $\mathrm{HVc}$ from its second major projection target, area $\mathrm{X}$ of the anterior forebrain (Fig. 9), should also cause motif suspension. Additionally, because
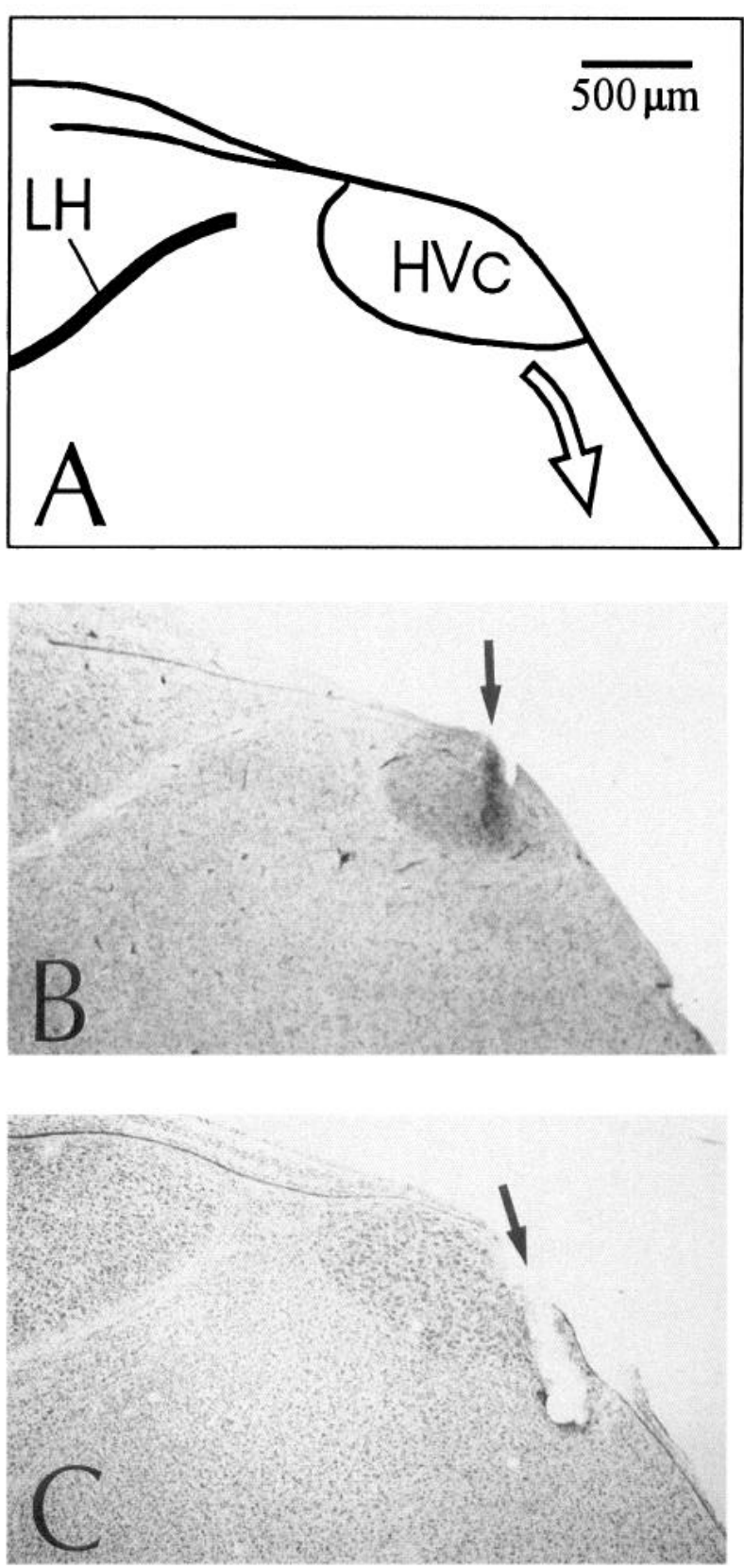

Figure 6. A, Drawing of part of a parasagittal brain section at the level of $\mathrm{HVc}$ showing the borders of $\mathrm{HVc}(\mathrm{HVc}$ is a large-celled area that stains more darkly than its surrounding in Nissl-stained sections) as well as the path of the fiber tract from HVc to RA (open arrow) that would be seen clearly in silver-stained sections. Anterior is to the left; dorsal is up. $L H$, lamina hyperstriatica. $B$, Photomicrograph of the tract created by a chronic stimulating electrode in a parasagittal brain section stained with cresyl violet. The arrow indicates the axis of electrode track. The tip of this electrode was located in HVc. Note the gliosis (dark staining) along the track and at the electrode tip. $C$, Similar section from a different animal in which the tip of the chronic electrode was located beyond the ventral border of HVc but in the HVc-to-RA tract. The shank of the chronic electrode created a hole in this section. Scale bar in $A$ applies also to $B$ and $C$.

area $\mathrm{X}$ is not necessary for adult song production (Sorhrabji et al., 1990; Scharff and Nottebohm, 1991), it provided a stimulation site that would activate $\mathrm{HVc}$ antidromically without directly stimulating any other part of the motor pathway for singing. 


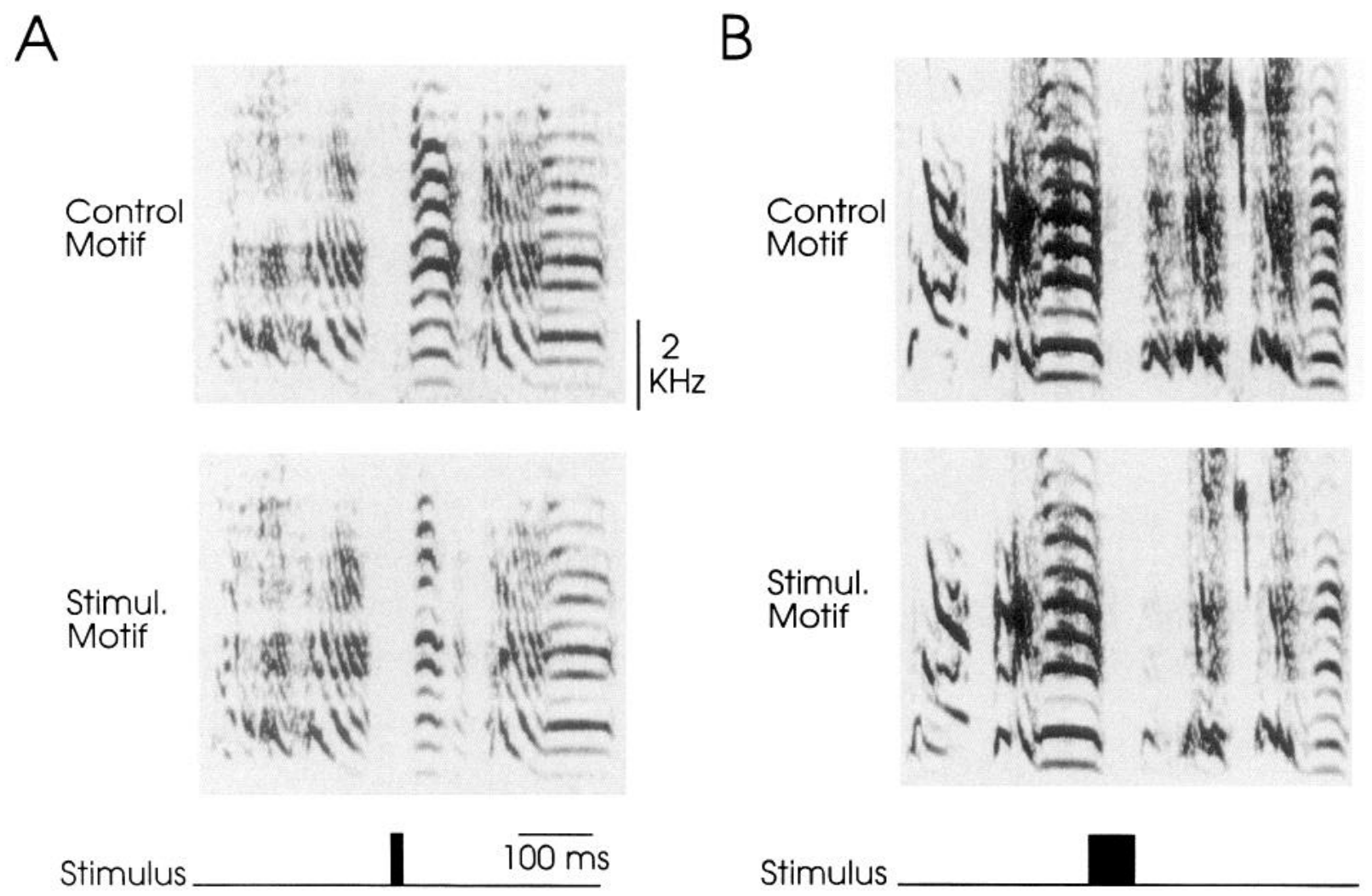

Figure 7. Effect on singing of briefly stimulating RA. A, The upper spectrogram illustrates a control motif and the lower spectrogram a motif sung by the same bird during which a stimulus to the right RA was delivered at the time shown by the Stimulus trace (bottom). Note that the relative timing of motif syllables was preserved following the stimulus, although the syllable immediately following the stimulus was distorted. (When the bird was quiescent, the same stimulus did not evoke any vocalization.) $B$, Same conventions as in $A$. In a different bird, the syllable distortion due to stimulating the left RA was made more clear by increasing the stimulus train duration to $70 \mathrm{msec}$. Stimuli applied through other electrodes with tips located just beyond the medial or ventral border of RA (by 150-585 $\mu \mathrm{m}$ ) had no effect on either the acoustic structure of syllables or the temporal pattern of motifs $(N=7$; data not shown). Calibration in $A$ also applies to $B$.

We found that stimulating area $\mathrm{X}$ unilaterally with low current intensities yielded a relatively low percentage of motif suspension $(28.3 \pm 6.4 \% ; N=3$; data not shown). However, stimulating at high intensities led to motif suspensions as consistently as did direct $\mathrm{HVc}$ stimulation (Fig. 9, group 3; $70.0 \pm 20.6 \%$; $N=4$; compare with Fig. 8, group 1).

Although strongly stimulating area X might lead to transynaptic activation of L-MAN (via activation of the medial nucleus of the dorsolateral thalamus, DLM; see Fig. 9), this cannot be the basis for the resulting motif suspensions because stimulating L-MAN directly does not cause motif suspension. It is more likely that high-intensity $\mathrm{X}$ stimulation activated $\mathrm{HVc}$ terminals in $\mathrm{X}$, leading to antidromic activation of $\mathrm{HVc}$ and thus to motif suspension.

In summary, motifs are perturbed as consistently when $\mathrm{HVc}$ is activated antidromically (by strongly stimulating area RA or $\mathrm{X})$ as when $\mathrm{HVc}$ is stimulated directly. These results strongly support our previous conclusion that it is not necessary to alter
Figure 8. Stimulating HVc but not RA neurons perturbed the song pattern. The mean percentage of stimuli that perturbed the motif pattern is shown for groups of stimulation sites located in the same brain areas. (Motifs were identified as having perturbed patterns when their durations were more than two standard deviations from the mean duration of unstimulated motifs.) Numbers in the circuit diagram to the left correspond to numbered bars in the right bar graph.

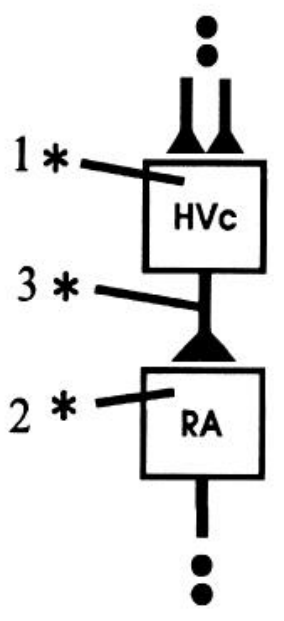



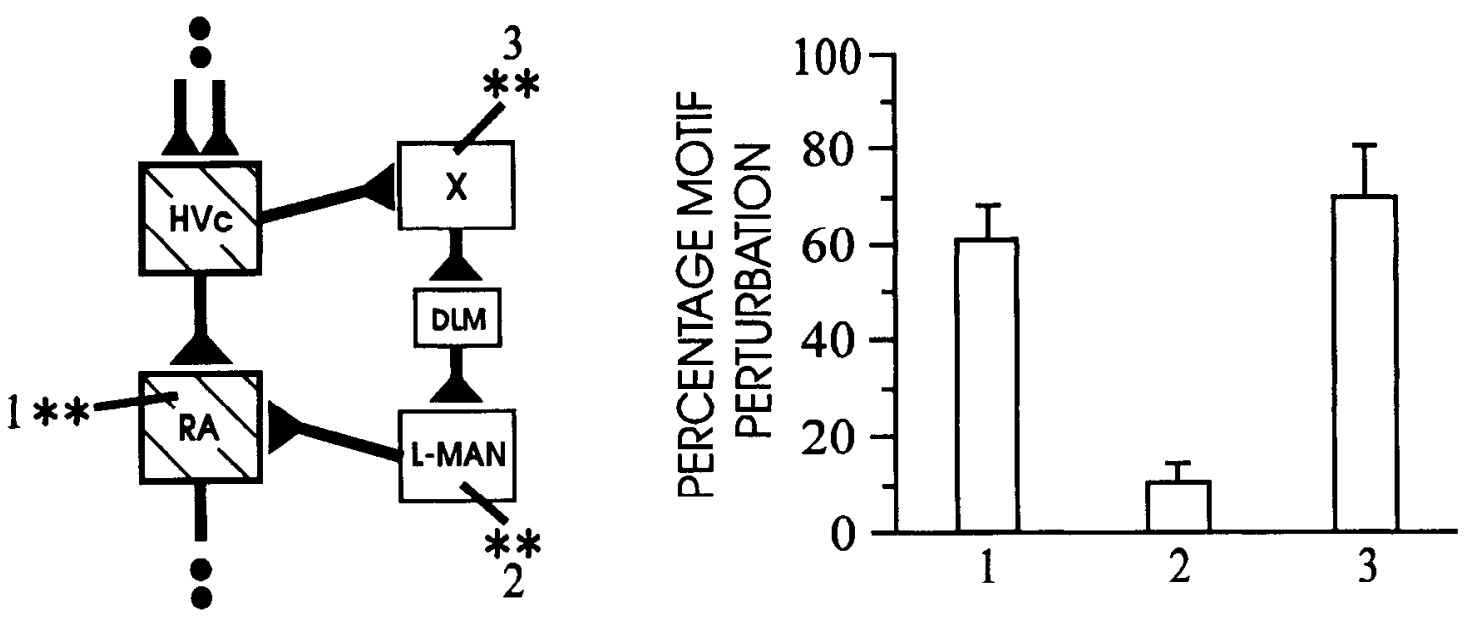

Figure 9. Antidromically activating $\mathrm{HVc}$ from $\mathrm{RA}$ or $\mathrm{X}$ perturbed the song pattern. Brain areas that are necessary for normal singing are hatched in the circuit diagram (left). Area $\mathrm{HVc}$ projects to $\mathrm{RA}$ as well as to area $\mathrm{X}$, which sends a projection to the medial nucleus of the dorsolateral thalamus $(D L M)$. Neurons in DLM in turn project to L-MAN (Okuhata and Saito, 1987; Bottjer et al., 1989). The numbers in the circuit diagram to the left correspond to the numbered bars in the right bar graph. The percentage motif perturbation for these electrode groups was calculated for stimuli with high current intensities $(45-70 \mu \mathrm{A})$, as implied by the double asterisks.

the activity of neurons that project to $\mathrm{HVc}$, such as those in areas NIf or Uva, to perturb motif patterning. Both the fibers and terminals of NIf and Uva neurons are at least $2 \mathrm{~mm}$ away from either RA or X, making it highly unlikely that they were affected by even high-intensity stimulation of RA or X. Nevertheless, song patterning was perturbed consistently by these stimuli.

Latencies to motif suspension. If strongly stimulating RA or area $X$ causes motif suspension by antidromically activating $\mathrm{HVc}$ neurons, then stimulating these areas should lead to motif suspension slightly later than stimulating $\mathrm{HVc}$ directly because of the conduction time needed for antidromic action potentials to travel to HVc.

For those stimuli in HVc, RA, and X that triggered a motif suspension, we obtained the mean time from the onset of the stimulus to the moment when the motif was suspended (Fig. 10). This latency to motif suspension was shortest with $\mathrm{HVc}$ stimulation, followed by $\mathrm{RA}$ and $\mathrm{X}$ stimulation $\left(\mathrm{HV}_{\mathrm{c}}=69.6\right.$ $\pm 2.3 \mathrm{msec} ; \mathrm{RA}=78.9 \pm 1.5 \mathrm{msec} ; \mathrm{X}=93.8 \pm 7.4 \mathrm{msec}$; ANOVA, $F=31.64 ; P<0.001)$. These results are consistent with antidromic activation of $\mathrm{HVc}$ when $\mathrm{RA}$ or $\mathrm{X}$ are strongly stimulated. They also provide additional evidence against the possibility that stimulating $\mathrm{HVc}$ triggered motif suspension simply by causing inappropriate firing of RA neurons. Such an explanation would have predicted that motifs be suspended more rapidly when stimulating RA than $\mathrm{HVc}$.

\section{Discussion}

The main finding of this study is that unilaterally stimulating $\mathrm{HV}_{\mathrm{c}}$ in singing zebra finches distorts the acoustic structure of ongoing syllables, suspends ongoing motifs, and rearranges the temporal pattern of ongoing strophes, whereas only syllable distortion results from unilaterally stimulating $\mathrm{RA}$, to which $\mathrm{HVc}$ directly projects. We showed also that it is sufficient to alter exclusively the firing pattern of $\mathrm{HVc}$ neurons that project to RA in order to perturb song patterning.

We draw from the present results two main conclusions on the neural control of singing by zebra finches: (1) neurons located in the telencephalic area HVc participate directly in generating the syllable sequence and tempo of the motif; (2) nonauditory feedback pathways to the telencephalon exist to coordinate the two hemispheres during singing.

\section{Motor programming by the telencephalon}

Konishi (1965) first showed that the vocalizations of adult songbirds remain highly stereotyped after deafening, indicating that the motor control of each syllable is not guided by auditory feedback from preceding syllables (or from earlier parts of the same syllable). These results led to the hypothesis that song control involves "central motor programs." However, deafening removes only one means by which animals could monitor their song output. It remained possible that other forms of sensory feedback, such as proprioception from the vocal tract or the respiratory musculature, could provide sufficient information to direct singing. Nottebohm (1967) partly addressed this issue by denervating the syrinx in order to alter singing-related pro-

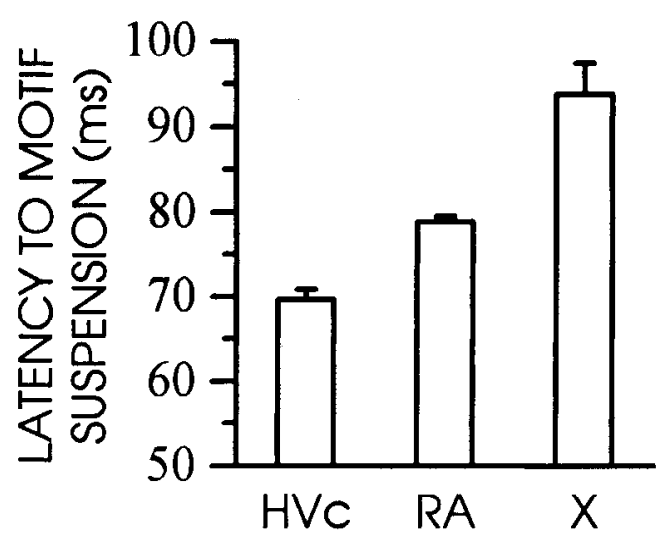

Figure 10. Motifs are suspended most rapidly when HVc neurons are perturbed most directly. The mean latency to motif suspension (time between stimulus onset and suspension of the ongoing motif) is shown for different groups of stimulation sites. Each bar represents the mean of means from individual sites (four $\mathrm{HVc}$, five RA, and four $\mathrm{X}$ sites). Only stimuli that caused motifs to be suspended were used to calculate the latency to suspension. Therefore, latency values for RA and X stimulation were obtained from high-intensity stimuli. 


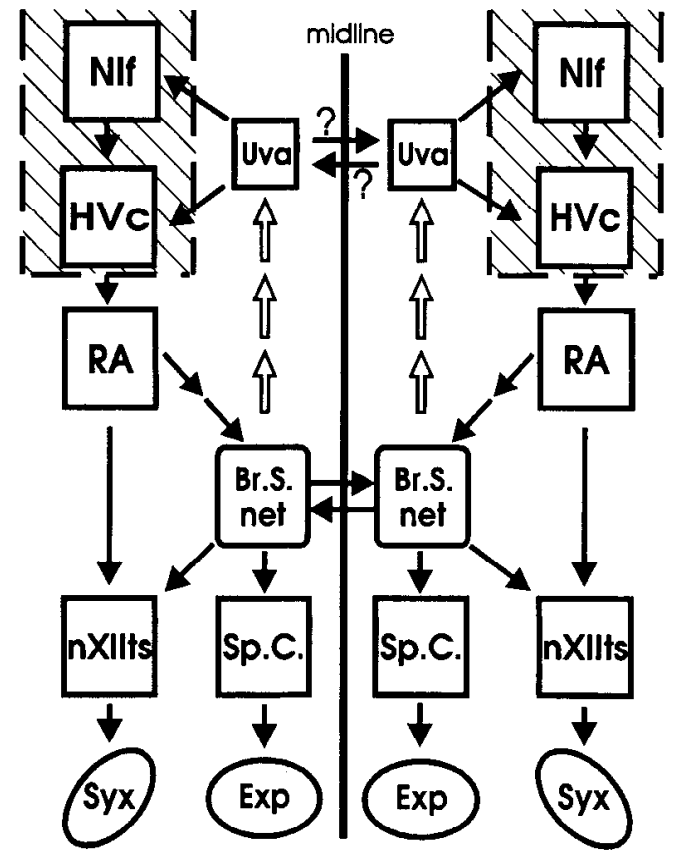

Figure 11. A network diagram of the song motor pathway localizing the role of organizing the syllable sequence and tempo of the motif to the brain areas inside the hatched box with dashed outline. Stimulating area NIf also perturbs song patterning (F. T. Vu and Y. Kuo, unpublished observations). Br.S. net, brainstem network that integrates the respiratory system with syringeal activity during song (Gurney, 1981; Wild and Arends, 1987; Wild, 1993, 1994). Sp.C., spinal cord; $S y x$, syrinx; Exp, expiratory abdominal muscles. Solid arrows, anterograde projections; open arrows, possible feedback pathway involved in interhemispheric coordination; a sequence of end-to-end arrows implies a multisynaptic pathway. Question marks, whether Uva is bilaterally connected is controversial.

prioception. He found that a stereotyped singing pattern persisted (as characterized by syllable durations and their spacing) even though the loss of syringeal control distorted proprioception from the vocal tract as well as the acoustic shape of each syllable. These results, like those from deafening experiments, are consistent with central programming but do not demonstrate it. The involvement of motor programs in complex behaviors such as birdsong is difficult to demonstrate conclusively with deafferenting experiments because the deafferentation needs to be complete and thus is often impractical.

The present study employed a more decisive strategy than partial deafferentation to test the motor programming hypothesis. The aim was to localize at least part of the motor program to a discrete part of the song control network by demonstrating that briefly perturbing this area alters the subsequent singing pattern. Additionally, we needed to show that perturbing the motor pathway "downstream" from this area fails to alter the behavioral pattern, indicating that simply perturbing motor performance without perturbing motor programming is not suffcient to alter song patterning. We discuss below the extent to which our findings satisfy these aims.

The finding that briefly altering the firing pattern in RA corrupts the acoustic structure of ongoing syllables but does not alter the motif pattern implies that the control of each syllable does not depend on the successful performance of the previous syllable. This conclusion is also supported by the previous deafening and syringeal denervation results, which have been ob- tained from zebra finches as well (Price, 1979; Simpson and Vicario, 1990; Nordeen and Nordeen, 1992). Electrical stimulation of RA probably perturbed motor performance more pervasively than syringeal denervation because the neural control signals from RA are distributed to multiple effector systems involved in singing (Vicario, 1991; Wild, 1993, 1994). In fact, the effects of RA stimulation were often to reduce the sound amplitude of ongoing syllables as well as to distort their structure (Fig. 7), suggesting both a transient reduction of expiratory drive and inappropriate control of the syrinx. Thus, the present results are more indicative of central generation of the motif pattern because the manipulation altered sensory feedback more extensively than does deafening or syringeal denervation.

The preserved motif pattern following RA stimulation implies that, if a localized patterning network for the syllable sequence of the motif exists, RA is not part of this network. Furthermore, the observation that stimulating HVc readily alters motif patterning argues against the possibility that a patterning network for the motif resides below RA (in the brainstem) because it is highly unlikely that such a brainstem patterning network could be perturbed easily by stimulating $\mathrm{HVc}$ but not by stimulating $\mathrm{RA}$, the only area in the motor pathway interposed between $\mathrm{HVc}$ and the brainstem (see Fig. $1 B$ ). Our finding that strongly stimulating RA leads to a pattern change later than occurs with $H V_{c}$ stimulation also contradicts this possibility because RA would be more closely linked than $\mathrm{HVc}$ to a brainstem patterning network and thus should disturb it more rapidly.

These observations thus suggest that the syllable sequence and tempo of the motif are generated by a network that resides in brain areas above RA and that includes HVc. During singing, the pattern is imposed on RA and lower structures in the motor pathway. The identification of the discrete telencephalic area $\mathrm{HVc}$ as at least part of the motor programming network for the motif pattern provides the most direct evidence to date that specific networks of neurons in the telencephalon store and generate motor programs for skilled sequences of movements.

\section{Interhemispheric coordination in song control}

A long-standing issue in the motor control of birdsong is the coordination nccded to control this bilaterally organized behavior. The present results suggest the existence of nonauditory feedback pathways to the telencephalon that serve to coordinate the two hemispheres during singing. We discuss the evidence for such feedback control and propose testable hypotheses on its neural basis.

Although birdsong involves neural activity on both sides of the brain (McCasland, 1987) and independent control of the two halves of the syrinx (Suthers, 1990), we successfully altered the song pattern by perturbing the neural activity in $\mathrm{HVc}$ on either side alone. This indicates that the unperturbed HVc (on either side) did not continue by itself to drive the periphery to complete the motif pattern. Furthermore, the finding that the motif following the suspended motif begins earlier than it would have if a stimulus had not been given implies that the patterning network in the contralateral HVc was first suppressed (less than $70 \mathrm{msec}$ after stimulus onset) and then triggered to begin a new motif synchronously with the HVc on the stimulated side. Because neither $\mathrm{HVc}$, NIf, nor RA is bilaterally interconnected (Fig. 11), the resetting of the contralateral patterning network is likely triggered by feedback pathways to the telencephalon from brain areas caudal to it. These feedback pathways are not 
exclusively auditory because $\mathrm{HVc}$ stimulation also perturbs song patterning by deaf birds.

We propose that the feedback resetting of the contralateral side is a result of detection of a mismatch in the control signals for singing from the two sides of the brain (produced by perturbing motor patterning and not simply motor performance on the stimulated side). We suggest that the thalamic nucleus Uva is a likely relay station for feedback coordinating signals to the telencephalon because of its direct projections to HVc and NIf (Nottebohm et al., 1982; Fig. 11). Consistent with this role, electrical stimulation of RA elicits responses in some $U$ va single units in quiescent zebra finches (Okuhata and Nottebohm, 1992). Additionally, Williams and Vicario (1993) found that lesioning Uva bilaterally has little effect on the structure of syllables or motifs (see also McCasland, 1987) but alters the organization of strophes by greatly reducing the number of motifs per strophe and increasing the intervals between motifs and the number of introductory notes (and calls) sung between motifs. This finding could be interpreted as a lesion-induced difficulty in initiating motifs within strophes, which would be a predicted outcome of lesioning an area involved in interhemispheric coordination.

\section{Plasticity of telencephalic programming networks}

We have shown that a discrete telencephalic area participates directly in patterning song behavior. Thus, like the brainstem and spinal cord, the telencephalon contains localized neural networks for specific motor programs. The question arises as to what difference might exist between birdsong and other patterned behaviors like respiration, mastication, and locomotion such that the song-patterning network is located in the telencephalon, whereas the networks for the latter behaviors reside in the brainstem or spinal cord. We propose that the key difference is that birdsong is learned by reference to an external model, whereas rhythmic behaviors like respiration do not need to be taught. Song develops abnormally if the young are deprived of an adult tutor (Immelmann, 1969). The need for an appropriate external model and for auditory feedback during vocal practice (Konishi, 1965) dictates the need for a pattern-generating motor network that is initially highly modifiable by external input. Perhaps this developmental plasticity is a common characteristic of motor programming networks in the telencephalon.

\section{References}

Alexander GE, DeLong MR, Crutcher MD (1992) Do cortical and basal ganglionic motor areas use "motor programs" to control movement? Behav Brain Sci 15:656-665.

Bernstein NA (1967) The coordination and regulation of movements. Oxford: Pergamon.

Bock G, O'Connor M, Marsh J (1987) Motor areas of the cerebral cortex. Chichester: Wiley.

Bottjer SW, Miesner EA, Arnold AP (1984) Forebrain lesions disrupt development but not maintenance of song in passerine birds. Science 224:901-903.

Bottjer SW, Halsema KA, Brown SA, Miesner EA (1989) Axonal connections of a forebrain nucleus involved with vocal learning in zebra finches. J Comp Neurol 279:312-326.

Brinkman C, Porter R (1979) Supplementary motor area in the monkey: activity of neurons during performance of a learned motor task. J Neurophysiol 42:681-709.

Carter MC, Shapiro DC (1984) Control of sequential movements: evidence for generalized motor progrants. J Neurophysiol 52:787796.

Chandler SH, Goldberg LJ (1984) Differentiation of the neural pathways mediating cortically induced and dopaminergic activation of the central pattern generator (CPG) for rhythmical jaw movements in the ancsthctizcd guinea pig. Brain Res 323:297-301.

Evarts EV (1968) Relation of pyramidal tract activity to force exerted during voluntary movement. J Neurophysiol 31:14-27.

Feldman JL (1986) Neurophysiology of respiration in mammals. In: Handbook of physiology, Sect 1, The nervous system (Bloom FE, ed), pp 463-524. Bethesda, MD: American Physiology Society.

Ghez C, Hening W, Gordon J (1991) Organization of voluntary movement. Curr Opin Neurobiol 1:664-671.

Grillner S, Wallen P (1985) Central pattern generators for locomotion, with special reference to vertebrates. Annu Rev Neurosci 8:233-261.

Grillner S, Wallen P, Brodin L, Lansner A (1991) Neuronal network generating locomotor behavior in lamprey. Annu Rev Neurosci 14: $169-200$.

Gurney ME (1981) Hormonal control of cell form and number in the zebra finch song system. J Neurosci 1:658-673.

Humphrey DR, Freund HJ (1991) Motor control: concepts and issues. Chichester: Wiley.

Immelmann K (1969) Song development in the zebra finch and other estrildid finches. In: Bird vocalizations (Hinde RA, ed), pp 61-77. Cambridge: Cambridge UP.

Kalaska JF, Crammond DJ, Cohen DAD, Prud'homme M, Hyde ML (1992) Comparison of cell discharge in motor, premotor, and parietal cortex during reaching. In: Control of arm movement in space: neurophysiological and computational approaches (Caminiti $\mathbf{R}$, Johnson PB, Burnod Y, eds), pp 129-146. Berlin: Springer.

Konishi M (1965) The role of auditory feedback in the control of vocalizations in the white-crowned sparrow. $Z$ Tierpsychol 22:770783.

Konishi M (1985) Birdsong: from behavior to neuron. Annu Rev Neurosci 8:125-170.

Konishi M (1989) Birdsong for neurobiologists. Neuron 3:541-549.

Kubota M, Saito N (1991) NMDA receptors participate differentially in two different synaptic inputs in neurons of the zebra finch robust nucleus of the archistriatum in vitro. Neurosci Lett 125:107-109.

Marsden CD, Rothwell JC, Day BL (1984) The use of peripheral feedback in the control of movement. Trends Neurosci 7:253-257.

McCasland IS (1987) Neuronal control of bird song production. J Neurosci 7:23-39.

Mooney R (1992) Synaptic basis for developmental plasticity in a birdsong nucleus. J Neurosci 12:2464-2477.

Mooney R, Konishi M (1991) Two distinct inputs to an avian song nucleus activate different glutamate receptor subtypes on individual neurons. Proc Natl Acad Sci USA 88:4075-4079.

Mushiake H, Inase M, Tanji J (1991) Neuronal activity in the primate premotor, supplementary, and precentral motor cortex during visually guided and internally determined sequential movements. J Neurophysiol 66:705-718.

Nordeen KW, Nordeen EJ (1992) Auditory feedback is necessary for the maintenance of stereotyped song in adult zebra finches. Behav Neural Biol 57:58-66.

Nottebohm F (1967) The role of sensory feedback in the development of avian vocalizations. In: Proceedings of the 14th International Ornithology Congress (Snow DW, ed), pp 265-280. Oxford: Blackwell.

Nottebohm F, Stokes TM, Leonard CM (1976) Central control of song in the canary, Serinus canarius. J Comp Neurol 165:457-486.

Nottebohm F, Kelley DB, Paton JA (1982) Connections of vocal control nuclei in the canary telencephalon. J Comp Neurol 207:344 357.

Okuhata S, Nottebohm F (1992) Nucleus Uva might be part of a feedback circuit for song processing. Soc Neurosci Abstr 18:527.

Okuhata S, Saito N (1987) Synaptic connections of thalamo-cerebral vocal nuclei of the canary. Brain Res Bull 18:35-44.

Pearson KG (1993) Common principles of motor control in vertebrates and invertebrates. Annu Rev Neurosci 16:265-297.

Pearson KG, Fourtner CR (1975) Nonspiking interneurons in walking system of the cockroach. J Neurophysiol 38:33-52.

Price PH (1979) Developmental determinants of structure in zebra finch song. J Comp Physiol Psychol 93:260-277.

Rothwell JC, Traub MM, Day BL, Obeso JH, Thomas PK, Marsden CD (1982) Manual motor performance in a deafferented man. Brain 105:515-542.

Rothwell JC, Day BL, Thompson PD, Marsden CD (1989) Interruption of motor programmes by electrical or magnetic brain stimulation in man. Prog Brain Res 80:467-472. 
Sanes JN, Mauritz KH, Dalakas MC, Evarts EV (1985) Motor control in humans with large-fiber sensory neuropathy. Hum Ncurobiol 4:101114.

Scharff C, Nottebohm F (1991) Behavioral deficits following lesions of various parts of the zebra finch song system: implications for vocal learning. J Neurosci 11:2896-2913.

Selverston AI, Moulins M (1985) Oscillatory neural networks. Annu Rev Physiol 47:29-48.

Simpson HB, Vicario DS (1990) Brain pathways for learned and unlearned vocalizations differ in zebra finches. J Neurosci 10:15411556.

Sohrabji F, Nordeen EJ, Nordeen KW (1990) Selective impairment of song learning following lesions of a forebrain nucleus in the juvenile zebra finch. Behav Neural Biol 53:51-63.

Sossinka R, Böhner J (1980) Song types in the zebra finch Poephila guttata castanotis. Z Tierpsychol 53:123-132.

Suthers RA (1990) Contributions to birdsong from the left and right sides of the intact syrinx. Nature 347:473-477.

Vicario DS (1991) Organization of the zebra finch song control system: II. Functional organization of outputs from nucleus robustus archistriatalis. J Comp Neurol 309:486-494.
Vu ET, Mazurek ME, Kuo Y (1993) Hierarchical organization of brain areas subserving zebra finch learned vocalizations. Soc Neurosci Abstr 19:1015.

Wild JM (1993) The avian nucleus retroambigualis: a nucleus for breathing, singing and calling. Brain Res 606:319-324.

Wild JM (1994) Descending projections of the songbird nucleus robustus archistriatalis. J Comp Neurol, in press.

Wild JM, Arends JJA (1987) A respiratory-vocal pathway in the brainstem of the pigeon. Brain Res 407:191-194.

Williams $H$ (1989) Multiple representations and auditory-motor interactions in the avian song system. Ann NY Acad Sci 563:148-164.

Williams H, Vicario DS (1993) Temporal patterning of song production: participation of nucleus uvaeformis of the thalamus. J Ncurobiol 24:903-912.

Yeomans JS (1990) Principles of brain stimulation. New York: Oxford UP.

Young D (1989) Nerve cells and animal behaviour. Cambridge: Cambridge UP.

Lann R (1985) Ontogeny of the zebra finch distance call: I. Effects of cross-fostering to bengalese finches. $Z$ Tierpsychol $68: 1-23$. 